\title{
PROFESSORES CURSISTAS DO PNAIC E SUAS CONCEPÇÕES DOS SOBRE A PRODUÇÃO ESCRITA
} INFANTIL

\section{PNAIC COURSE TEACHERS AND THEIR CONCEPTIONS ON CHILDREN'S WRITTEN PRODUCTION \\ PROFESORES CURSISTAS DEL PNAIC Y SUS CONCEPCIONES SOBRE LA PRODUCCIÓN ESCRITA INFANTIL}

\author{
Francisca Edilma Braga Soares Aureliano ${ }^{1}$ \\ Mácio Raulino Alves ${ }^{2}$ \\ 1. Pedagogia. Doutorado em Educação. UFRN. E-mail: edilmaaureliano@ hotmail.com \\ 2. Pedagogia. Especialista em Educação. UERN- E-mail: macioraulino@gmail.com.
}

\begin{abstract}
RESUMO: O artigo apresenta os resultados de uma pesquisa que tem como objetivo analisar as concepções teóricas e metodológicas que as professoras do $1^{\circ} \mathrm{e}$ do $2^{\circ}$ ano do Ensino Fundamental de uma escola pública, construíram a partir do curso de formação continuada do Pacto Nacional pela Alfabetização na Idade Certa (PNAIC) quanto a produção escrita no ciclo de alfabetização. O estudo teve como sujeitos colaboradoras duas professoras alfabetizadoras que participaram do curso de formação do referido programa formativo. Trata-se de um estudo qualitativo e crítico (LUDKE; ANDRÉ, 1986) e teve como procedimentos de estudo dos dados empíricos das entrevistas semiestruturadas a Análise de Conteúdo do tipo categorial (BARDIN, 1977), bem como foi realizada a revisão da literatura sobre formação continuada, produção escrita e alfabetização e o estudo dos documentos do programa. Os resultados mostram um distanciamento das concepções teórico-metodológicas das professoras com as orientações estabelecidas pelo PNAIC, visto que não demonstram em seus discursos apropriação dos principais conceitos, objetivos e encaminhamentos metodológicos que a formação continuada abordava, quanto a produção da escrita das crianças, e a ausência desses conhecimentos as conduzia a um retorno as estratégias pedagógicas que prioriza a repetição e a memorização de letras e sílabas, oriundas do ensino tradicional para alfabetizar.
\end{abstract}

Palavras-chave: Alfabetização. Formação continuada. PNAIC. Escrita infantil. Professores alfabetizadores.

Recebido em: 28/07/2021

Aprovado em: 11/11/2021
ABSTRACT: The article presents the results of a research that aims to analyze the theoretical and methodological conceptions that the teachers of the 1st and 2nd year of elementary school of a public school, built from the continuing education course of the National Pact for Literacy in Age Certain (PNAIC) regarding written production in the literacy cycle. The study had as collaborating subjects two literacy teachers who participated in the training course of the aforementioned training program. This is a qualitative and critical study (LUDKE; ANDRÉ, 1986) and its procedures for studying empirical data from semistructured interviews were Content Analysis of categorical type (BARDIN, 1977), as well as a review of the literature on continuing education, written production and literacy and the study of official documents of the program. The results show a distancing from the theoretical-methodological conceptions of the teachers with the guidelines established by the PNAIC, as they do not demonstrate in their discourses the appropriation of the main concepts, objectives and methodological guidelines that continuing education addressed, regarding the production of children's writing, and the absence of this knowledge led them to a return to pedagogical strategies that prioritize the repetition and memorization of letters and syllables, derived from traditional teaching to teach literacy.

Keywords: Literacy. Continuing formation. PNAIC. Children's writing. Literacy teachers.
RESUMEN: El artículo presenta los resultados de una investigación que tiene como objetivo analizar las concepciones teóricas y metodológicas que las profesoras del $1^{\circ}$ y del $2^{\circ}$ año de la Enseñanza Fundamental de una escuela pública construyeron a partir del curso de formación continuada del Pacto Nacional para la Alfabetización en la Edad Apropiada (PNAIC) en relación a la producción escrita en el ciclo de alfabetización. El estudio tuvo como sujetos colaboradoras dos profesoras alfabetizadoras que participaron del curso de formación del referido programa formativo. Se trata de un estudio cualitativo y crítico (ANDRÉ; LUDKE, 1986) y utilizó como procedimientos de análisis de los datos empíricos de las entrevistas semiestruturadas el Análisis de Contenido del tipo categorial (BARDIN, 1977), además de la revisión de la literatura sobre formación continuada, producción escrita y alfabetización y el estudio de los documentos oficiales del programa. Los resultados muestran un alejamiento de las concepciones teórico-metodológicas de las profesoras en cuanto a las orientaciones establecidas por el PNAIC, puesto que las docentes no demuestran en sus discursos apropiaciones de los principales conceptos, objetivos y orientaciones metodológicos que la formación continuada abordaba, en cuanto a la producción de la escrita de los niños, y la ausencia de esos conocimientos las conducía a un regreso a las estrategias pedagógicas que priorizan la repetición y la memorización de letras y sílabas, oriundas de la enseñanza tradicional para alfabetizar.

Palabras-clave:

Alfabetización. Formación continuada. PNAIC. Escrita infantil. Profesores alfabetizadores.

Todo o conteúdo deste periódico está licenciado com uma licença Creative Commons (CC BY-NC-ND 4.0 Internacional), exceto onde está indicado o contrário. 


\section{Introdução}

A alfabetização no Brasil durante seu percurso histórico passou por várias mudanças, tendo como finalidade a diminuição do índice de analfabetismo que resultou do descaso do Estado na garantia da educação pública a todos os brasileiros desde o período da colonização. A partir do final da década de 1980, com a instauração do processo de redemocratização do país, o Estado passou a investir em políticas direcionadas a erradicação do analfabetismo adulto, e a formação continuada de professores alfabetizadores.

Atualmente pelos marcos regulatórios, a alfabetização até os 8 anos de idade constitui a Meta 5 do Plano Nacional de Educação (PNE) de 2001 (BRASIL, 2001) e se repetiu no PNE de 2014 (BRASIL, 2014), com uma redução do prazo da alfabetização para 7 anos de idade na Política Nacional de Alfabetização, publicada em 2019 (BRASIL, 2019). No intuito de atender a referida meta do PNE de 2001, o Ministério da Educação (MEC), lança o Pacto Nacional Pela Alfabetização na Idade Certa (PNAIC), através da portaria $n^{\circ} 867$ de 04 de Julho de 2012 (BRASIL, 2012a), se configurando como um compromisso entre os entes federativos para realização de ações governamentais, entre elas, cursos de formação continuada de professores, com o propósito de melhorar os indicadores nas avaliações nacionais em Língua Portuguesa e Matemática.

O público alvo do programa foram os professores que atuavam $1^{\circ}, 2^{\circ}$ e $3^{\circ}$ ano das redes públicas de ensino (Ciclo de Alfabetização), com o objetivo de capacitá-los para a compreensão do processo de alfabetização e contribuir para o desenvolvimento de competências que permitissem efetividade da prática docente para plena alfabetização até o final do $3^{\circ}$ ano de Ensino Fundamental. O caderno no 05 do curso de formação continuada do PNAIC, nomeado como "A oralidade, a leitura e a escrita no ciclo de alfabetização" (BRASIL, 2015, p. 112) orienta que a produção escrita deve ocorrer através de metodologias sistemáticas para proporcionar significação na aprendizagem com relação ao Sistema de Escrita Alfabética (SEA).

Esse caderno apresenta encaminhamentos teórico-metodológicos para o desenvolvimento de situações didáticas do professor com relação ao ensino da linguagem escrita. Diante dessas orientações que o programa formativo procuramos neste estudo responder a seguinte inquietação: que aproximações e distanciamentos entre os conhecimentos teórico-metodológicos as professoras demonstram ter construído na formação continuada do PNAIC sobre a produção da escrita diante das orientações que esse programa propôs? A pesquisa foi norteada pelo objetivo de analisar as concepções teóricas e metodológicas construídas pelas professoras alfabetizadoras ao longo do curso de formação continuada referido programa em relação a produção da escrita no ciclo de alfabetização.

Apresentamos inicialmente de forma sintetizada, a metodologia adotada para a realização do estudo, em seguida, o texto aborda a configuração do PNAIC como uma política de formação continuada a partir dos documentos oficiais e didáticos de implementação do programa. Dando continuidade. discutimos o referencial teórico que enfoca os conceitos que envolve a produção escrita no ciclo de alfabetização e os aspectos didáticos-pedagógicos que podem ser encaminhados para o aprendizado dessa produção. A última seção do texto enfatiza a discussão dos dados empíricos de forma crítica averiguando os conhecimentos que os docentes construíram na formação do PNAIC a partir do recorte das categorias: Trabalho com os nomes e Formação de Palavras. Por último, traçamos as considerações finais com a sínteses dos resultados e as contribuições do estudo para o cenário educacional e acadêmico. 


\section{Metodologia}

O estudo é um recorte de uma investigação realizada no Grupos de Pesquisa: Formação, Currículo e Ensino (FORMACE) do Curso de Pedagogia do Campus Avançado de Patu da Universidade do Estado do Rio Grande do Norte (UERN) que contou com a colaboração de pesquisadores da Universidade Federal do Rio Grande do Norte (UFRN).

Teve como base às orientações metodológicas da abordagem qualitativa, partimos do interesse de fazer um estudo sistematizado do objeto estudado, compreendendo as estruturas que estão por trás das falas dos sujeitos pesquisados. Ludke e André (1986) destacam que a pesquisa qualitativa parte da pretensão de envolver os dados descritivos que foram construídos através do pesquisador com a situação investigada.

Como instrumento metodológico utilizamos a entrevista semiestruturada, desenvolvida com duas professores que lecionam respectivamente no $1^{\circ}$ e $2^{\circ}$ ano do Ensino Fundamental na Escola Municipal Raimundo Nonato da Silva, localizada município de Patu/RN. No intuito de guardar as identidades das docentes, elas são identificadas no texto por P1 e P2.

Para realizar o tratamento dos dados, utilizamos a Análise do Conteúdo do tipo categorial, com base em Bardin (1977). Segundo Câmara (2013) a análise do conteúdo está dividida em três etapas: pré-análise, exploração do material e tratamento dos resultados e a inferência. Assim, esse modelo de análise caracteriza-se como um método empírico que busca a partir dos elementos das comunicações e dos materiais teóricos, interpretar o que se pretende alcançar como objetivo.

A partir desse paradigma metodológico, conseguimos interpretar e compreender as subjetividades construídas através das vivências das professoras pesquisadas e formular organizações categóricas das informações contidas em suas falas, tentando entender o sentido das comunicações e construir outros significados. Além da pesquisa de campo, realizamos o estudo da literatura que trata da formação continuada, produção escrita e do processo de alfabetização. Para melhor analisar os dados, tivemos como parâmetro os documentos oficiais dos PNAIC, como a portaria de implementação e os que orientam os conteúdos e a estrutura dos cursos de formação que eram promovidos para os professores.

\section{O PNAIC como política de formação continuada para professores alfabetizadores}

As políticas de formação continuada constituíram-se um importante requisito para a qualificação e atualização do trabalho docente no cenário educacional contemporâneo. Algumas pesquisas como a de Gatti (2008) destacam que a formação de professores está em questão devido às novas demandas do mundo do trabalho, exigindo um repensar no modo de ensinar e aprender, e pelos baixos desempenhos escolares nos últimos anos. Isso reforça a ideia que a formação continuada apresenta-se como uma possibilidade para o professor superar as possíveis dificuldades encontradas no processo de ensino e aprendizagem da leitura e da escrita.

O PNAIC é apresentado pelo MEC como uma política de formação continuada regularmente instituída em nível nacional pela Portaria no 867, de 04 de julho de 2012, (BRASIL, 2012a), fruto de um compromisso formal assumido pelos entes federativos: União, Distrito Federal, Estados e Municípios. Esse compromisso tinha por objetivo atender a meta 5 do Plano Nacional de Educação (PNE), o qual define que a alfabetização ocorra até o final do $3^{\circ}$ (terceiro) ano do ensino fundamental e tendo o professor como principal agente para atingir essa meta. Assim, o programa constituía-se através de um conjunto integrado 
de ações, de materiais pedagógicos e referenciais curriculares que foram disponibilizados pelo MEC para formação continuada dos professores alfabetizadores.

O Pacto em 2013 propunha cursos de formação continuada que contemplava o ensino de Língua Portuguesa, e Matemática em 2014. No entanto, só a partir de 2015 que o programa contemplou as demais áreas do conhecimento de forma contextualizada. Vale lembrar que a legitimidade política do PNAIC foi instituída em decorrência do programa Pró-Letramento ${ }^{1}$. O MEC considerou o programa bem sucedido, ao analisar as informações dos resultados do Instituto Nacional de Estudos e Pesquisas Anísio Teixeira (INEP). Esse programa tinha como principal objetivo metodológico, fortalecer os estudos e as práticas dos professores alfabetizadores que atuam no ciclo de alfabetização. De acordo com o caderno de formação do PNAIC (BRASIL, 2015, p. 23) esse ciclo deve levar em conta três partes importantes para o desenvolvimento das crianças:

1) o tempo da apropriação da cultura escolar, quando as crianças "aprendem a ser estudantes"; 2) o tempo para o trabalho de apropriação e consolidação do Sistema de Escrita Alfabética (SEA), considerando a complexidade desse sistema notacional; e 3) a aquisição de "mais autoconfiança das crianças na aprendizagem dos demais componentes, sem que haja a reprovação nesse início de escolarização".

O material formativo do programa (BRASIL, 2015, p. 48) propõem como um dos objetivos assegurar ao docente uma qualificação que lhe deem a capacidade de interagir por "[...] meio de textos escritos em diferentes situações e propósitos, compreender o Sistema de Escrita Alfabética, sendo capaz de ler e escrever, com autonomia, textos de circulação social que tratem de temáticas familiares ao aprendiz". A proposta de formação do PNAIC sobre a produção escrita encaminhava-se para capacitar o professor quanto a ter mais clareza e coerência sobre o que ensinar e como ensinar, através dos suportes metodológicos orientados. Desse modo, essa formação caracterizava-se por orientar as práticas pedagógicas a fim de introduzir, ampliar e consolidar o processo de ensino aprendizagem da escrita das crianças.

Promover o desenvolvimento das aprendizagens dos alfabetizandos era objeto norteador das orientações metodológicas do PNAIC, pois se configurava como um componente essencial para o aperfeiçoamento das práticas pedagógicas dos professores cursistas, permitindo o acesso aos fundamentos teóricos que encaminhava para uma mediação direcionada a apropriação da escrita alfabética e sua utilização na vida cotidiana.

Segundo o documento orientador do PNAIC (BRASIL, 2017) a formação continuada de professores como uma política nacional é entendida como um componente essencial para profissionalização docente, necessitando integrar-se à realidade da escola, respeitando e valorizando os diferentes saberes dos docentes. No que diz respeito à oferta do programa, os professores alfabetizadores eram convidados a participar de uma capacitação, com a oferta de suporte didático através do conjunto de cadernos que orientam os fundamentos teóricos metodológicos para garantir os direitos de aprendizagem das crianças, sendo que um desses direitos era a garantia da aprendizagem da escrita.

Cada município encaminhava professores formadores para os centros de formação localizados nas capitais dos estados para receberem a capacitação promovida pelas universidades vinculadas a Rede

\footnotetext{
${ }^{1}$ Programa de Formação Continuada de professores criado em 2006 pelo Ministério da Educação em parceria com as universidades públicas com a finalidade de melhorar a qualidade da aprendizagem em leitura e escrita, e matemática nas séries iniciais do ensino fundamental.
} 
Nacional de Formação dos Profissionais da Educação Básica (RENAFOR) objetivando que estes pudessem multiplicar os conhecimentos que recebiam. Compreendemos que os cursos direcionados de forma verticalizada sem a participação dos docentes ou da equipe pedagógica no seu planejamento, nem sempre correspondem as necessidades formativas destes profissionais, pois se configura dentro de um novo tecnicismo vinculado a formação docente, em que se compreende que a aprendizagem ocorre pela multiplicação do conhecimento, sem passar por processamentos individuais de aprendizagem como defende Vigotsky (2018).

O discurso apresentado nas orientações do PNAIC estava direcionado para a potencialização e aperfeiçoamento das práticas educativas dos professores alfabetizadores, incluindo os que atuam em turmas multisseriadas, pois defendia práticas inclusivas de atendimento às necessidades encontradas no contexto educacional brasileiro.

\section{A produção escrita no ciclo de alfabetização}

A linguagem escrita é considerada um artefato que a criança vai se apropriando durante o seu percurso escolar. Essa apropriação implica diferentes aprendizagens que servirão para novas aquisições na construção do seu conhecimento. No entanto, ensinar os alunos a serem produtores de suas próprias escritas, continua sendo um problema que permanece a preocupar os professores sobre qual melhor e mais eficaz método para aprendizagem das crianças.

Marcuschi (2008) ao analisar os processos de produção textual, mostra que em muitas escolas, os professores de Língua Portuguesa usam a produção de textos para o ensino da escrita. Contudo, não são diversificados os modos e estratégias de construção e utilização desses textos, nem suas finalidades na sociedade. De acordo com o autor, a inadequação do uso dos textos em sala de aula se materializa na ausência de elementos e critérios que poderiam ser trabalhados com os alunos.

Tendo em vista que muitas crianças concluem a primeira etapa do Ensino Fundamental com muitas deficiências na produção escrita, Koch e Elias (2017) destacam a importância do professor utilizar estratégias de ensino para o desenvolvimento dessa linguagem, pois a escrita faz parte de nossa vida, visto que somos constantemente solicitados a ler e a produzir textos escritos em diversas situações do dia a dia.

É importante entendermos que a leitura e a escrita estruturam nosso sistema de escrita que se complementam na formação do conhecimento exige um esforço cognitivo do aluno, e inserir essas duas tecnologias nas práticas sociais têm sido bastante discutidas por pesquisadores e estudiosos como Soares (2003), que destaca a alfabetização como um processo que deve estar inserida dentro das práticas do letramento. A esse respeito, Soares (2003, p. 14) enfoca que:

\footnotetext{
Dissociar alfabetização e letramento é um equívoco porque, no quadro das atuais concepções psicológicas, linguísticas e psicolinguísticas de leitura e escrita, a entrada da criança (e também do adulto analfabeto) no mundo da escrita ocorre simultaneamente por esses dois processos: pela aquisição do sistema convencional de escrita $-a$ alfabetização - e pelo desenvolvimento de habilidades de uso desse sistema em atividades de leitura e escrita, nas práticas sociais que envolvem a língua escrita - o letramento.
}

A alfabetização e letramento são termos utilizados para designar os indivíduos que fazem o uso da leitura e da escrita nas diferentes práticas sociais. Assim, para que a criança ganhe autonomia nas atividades dessas duas tecnologias, é preciso conhecer os princípios que estruturam o Sistema de Escrita Alfabética 
(SEA) para realizar reflexões acerca da relação sonora e gráfica das palavras, reconhecendo as representações das correspondências som-grafia. Por isso, a alfabetização e letramento relacionam-se ao envolver as vivências culturais que estão presentes no nosso dia a dia.

Autores como Morais, Albuquerque e Leal (2005) defendem o enfoque da escrita alfabética como sistema notacional, que precisa ser desenvolvido através de didáticas alfabetizadoras significativas, libertando-se dos "velhos" métodos associacionistas, permitindo o professor consiga alfabetizar letrando.

Assim, ao chegarem ao ambiente escolar, às crianças já dominam a língua falada, e quando entra em contato com a língua escrita sentem muita dificuldade, pois usam as marcas da oralidade que estão habituadas a falar no seu dia a dia. Com relação a essas dificuldades, Morais, Albuquerque e Leal (2005, p 49) dizem que "[...] a oportunidade de escrever quando ainda não se sabe, permite que a criança confronte hipóteses sobre a escrita, e pense em como ela se organiza, o que representa e para que serve". Desse modo, o professor poderá intervir de maneira ajustada para que os educandos consigam evoluir gradativamente de um nível para o outro, utilizando-se de estratégias metodológicas que conscientize os alunos sobre as exigências que são necessárias para produção textual.

Diante de tal contexto, a produção da escrita corresponde a uma atividade coerente e planejada que ocorre entre os sujeitos, e que deve ser orientada pelo professor os aspectos principais da organização e compreensão dos textos, como a clareza e precisão na linguagem gráfica utilizada, proporcionando que as crianças percebam os elementos que estruturam o seu texto, bem como o seu sentido de uma forma geral.

\section{Aspectos didáticos e pedagógicos da produção de texto no ciclo de alfabetização}

Os estudos referentes às práticas pedagógicas do trabalho com a produção escrita no Ciclo de Alfabetização destacam que ainda há a persistência de didáticas que ainda mantém um prisma reducionista com relação ao estudo da palavra, (ANTUNES, 2003). Essas limitações que ainda permanecem nas aulas de Português restringem consequentemente, os objetivos que a linguagem escrita poderia gerar para construção do conhecimento por parte das crianças.

A produção textual segundo Antunes (2003, p. 54) está associada a três etapas que se complementam para sua realização: “[...] o planejamento, a operação e a revisão". Assim, percebemos que a construção de um texto escrito não se reduz somente na codificação das ideias e dos sinais gráficos utilizados, mas também na capacidade de conseguir arquitetar e planejar o que será escrito, registrar no papel o que foi pensado, e avaliar/analisar o que foi escrito para conseguir elaborar um texto mais coeso e coerente.

Para o desenvolvimento da escrita alfabética das crianças, é importante também que elas possam desfrutar das diferentes práticas da escrita, sendo capaz de refletir sobre a formação e uso das palavras, e isto se dá por meio das representações gráficas e os sons que com compõe a escrita. Por isso, a efetividade das ações didáticas consciente sobre a produção de texto exige que os professores conheçam a forma que as crianças aprendem, a maneira como pensam a escrita e as formas de representação a respeito dela. Diante disso, Morais, Albuquerque e Leal (2005, p 51) afirmam que:

Para saber o que pensa o aprendiz sobre o sistema de escrita, é preciso solicitar que ele escreva palavras, frases ou textos que não lhe foram ensinados previamente e pedir que eles os leiam logo depois para grafá-los. [...] buscaremos, em cada nível, abordar: (1) as hipóteses que os alunos construíram; (2) os conhecimentos que ainda precisam ser construídos; (3) como o professor, de posse dos dados apontados por seus alunos, pode intervir, organizando seu planejamento e lançando desafios para que o aluno passe para outro nível; (4) sugestões de atividades adequadas as hipóteses de escrita apontadas pelos alunos. 
Assim, para que as práticas pedagógicas que vá de encontro com as necessidades cognitivas das crianças na sua heterogeneidade, se faz necessário criar estratégias de ensino, que sejam constantemente refletidas no cotidiano da sala de aula, pois o professor como mediador desse processo de ensinar a produção escrita dos alunos, deve criar situações didáticas que favoreçam o desenvolvimento de escritas significativas e orientadas no contexto da alfabetização.

De acordo com Antunes (2003) durante o início da escrita escolar, o ideal é que se crie, com os alunos, a prática do planejamento, a prática do rascunho, a prática das revisões de maneira que as primeiras versões dos textos sirvam de experiência para fazer e refazer os textos posteriores. Partindo desse pressuposto, a maturidade na atividade de escrever é uma conquista que se dá mediante a prática de revisão dos textos, tornando-se este um importante instrumento de qualificação da escrita dos alunos. A função do professor é proporcionar meios para conscientizar as crianças sobre as especificidades na construção da escrita e das exigências que são próprias dessa linguagem

Dessa maneira, é importante que o professor planeje e organize as atividades de acordo com a realidade da turma, sendo um profissional capaz de refletir sobre sua prática, e utilizando-se de métodos e estratégias para conseguir fazer com que as crianças compreendam e desenvolvam sua aprendizagem com relação ao SEA. Dentre essas estratégias para o ensino da escrita, a interação assume um papel importante quando o professor compreende a Zona de Desenvolvimento Proximal ${ }^{2}$ (ZDP) e intervém na aprendizagem do aluno, suas capacidades de construir sua própria escrita com autonomia e coerência, (CALKINS, HARTMAN, ZOE, 2008). Entendemos, dessa forma, que o professor ao interagir, precisa conhecer como a criança produz seu texto, como ela quer escrever, com que objetivo, e para quem ela está escrevendo, para que seja capaz de intervir para qualificar o que a criança está produzindo.

Nesse sentido, a aprendizagem da linguagem escrita pode ser vista como um processo construído através da linguagem nas interações e ações entre professores e alunos, tanto no plano individual quanto no plano coletivo. É por intermédio da linguagem, que os conceitos cotidianos vão dando lugar à elaboração de conceitos científicos: novas palavras são aprendidas e os significados das palavras corriqueiras vão sendo ampliados com novas acepções. Desse modo, a escrita entendida na perspectiva interacional, constitui-se de elementos fundamentais para coerência na produção textual, visto que é a partir da junção entre o texto escrito, o autor e o leitor que se pode possibilitar durante a mediação, as orientações necessárias para produção de textos coerentes.

Koch e Elias (2017) destacam que no ato da escrita, as crianças exploram e recorrem aos seus conhecimentos de mundo para construírem suas produções textuais. Sendo assim, as práticas sociais da escrita devem ser consideradas imprescindíveis para que a aprendizagem aconteça dentro e fora da escola, e que esse conhecimento sobre a utilização da escrita no meio social precisa ser valorizado pelo professor. Entretanto, vale mencionar que para que esses saberes externos à escola sejam de fato eficientes no trabalho do educador, é necessário considerar todas as particularidades dos alunos, tais como seus conhecimentos prévios, as culturas e os grupos sociais e econômicos em que as crianças se inserem.

Em conformidade com esse pensamento, Antunes (2003, p. 62) defende a ideia de que "as propostas para que os alunos escrevam textos devem corresponder aos diferentes usos sociais". De acordo com as orientações do PNAIC (BRASIL, 2015, p 63) as atividades do ensino do SEA devem ocorrer como um processo contínuo e progressivo, e ligado ao contexto das práticas do letramento. Dessa forma, que a

\footnotetext{
${ }^{2}$ A Zona de Desenvolvimento Proximal é um conceito central utilizado na psicologia sócio-histórica por Vygotsky (2018), na qual a criança consegue realizar suas tarefas com a mediação e ajuda de adultos ou de colegas mais avançados ou experientes.
} 
produção da escrita deve corresponder aquilo que se escreve dentro e fora da sala de aula, tornando seu ensino mais efetivo pelo uso de gêneros textuais que têm uma função social determinada na sociedade. Frade (2007, p 32) corrobora com esse pensamento quando enfatiza que:

Esse conceito deu visibilidade a fenômenos que são constituídos por ordenamentos mais amplos: o cultural, o social, o histórico e permite que compreendamos as condições socioculturais em que se dá a distribuição da cultura escrita dentro e fora da escola. As noções de letramento permitem compreender que quando se ensina a ler e escrever, se ensina também um modo de pensar o mundo "por escrito".

Desenvolver práticas de alfabetização colocando a escrita como ponto de partida exige a compreensão de que o ensino aprendizagem do sistema alfabético, e as práticas sociais em que a escrita está inserida no nosso dia a dia, é de extrema importância nesse momento globalizado que estamos vivendo, em que a leitura e escrita estão cada vez mais presentes na sociedade, seja nos meios tecnológicos de informação, seja nas revistas, jornais e em todos os contextos sociais, políticos e culturais. Por isso, o planejamento deve ser uma das principais ações feitas pelo professor para desenvolver atividades didáticas que propiciem a formação dos sujeitos produtores de texto, sendo capazes de adquirir conhecimentos não somente sociais, mas também do Sistema de Escrita Alfabética.

\section{A PRODUÇÃO ESCRITA E SUA RELAÇÃO COM OS CONHECIMENTOS CONSTRUÍDOS PELOS PROFESSORES NO PNAIC.}

A formação profissional de cada sujeito vai se fazendo e modificando de acordo com suas possibilidades e limitações, ressalvando suas características próprias, seus estudos, sua formação continuada, seus objetivos almejados, os conceitos e recursos disponíveis durante todo o curso que facilitarão suas atitudes pós-formação, buscando programar o que foi experimentado durante a formação inicial e continuada. Mesmo diante de muitos processos formativos, vão ser esses momentos que irão concretizar um profissional inovador e reflexivo, um docente com um novo olhar sobre a educação e com várias ramificações criando novos meios de saber fazer, a fim de redimensionar a prática alfabetizadora.

A formação do PNAIC contribui para organização das diferentes didáticas para o ensino do Sistema de Escrita Alfabética, possibilitando a sistematização dos conteúdos e objetivos a eles associados. Diante disso, fica evidente a importância do professor conhecer as propriedades do SEA para elaboração do planejamento com as atividades de correspondência grafo-fônicas, em que os alunos procuram palavras que iniciam com determinada letra ou sílaba, sendo essa uma atividade importante para trabalhar os nomes dos alunos (MORAIS, ALBUQUERQUE, LEAL, 2005).

Nesta seção do texto, apresentamos a análise crítica dos dados a partir das categorias: Trabalho com os nomes e Formação de Palavras construídas pelo procedimento Análise de Conteúdos orientado por Bardin (1977). Os enunciados a seguir marcam as repetições nos levou a organizar a primeira categoria: "trabalho com os nomes" pela repetição de sentidos:

Partindo do princípio da criança começa a aprender as letrinhas. Então a gente vai começar pelo nome dela. Quais as letras que formam o seu nome? E aí dentro daquele nome dela começar a trabalhar todas aquelas letrinhas. E dizendo que outras palavras, é... o as mesmas letras que formam o nome dela vão formar nome de outras crianças ou nome de outras pessoas. Então, a gente parte desse princípio. Começando do cotidiano da criança, do nome da criança, da ruazinha da criança de onde ela mora, de uma brincadeira de amarelinha é... amarelinha começa com qual letrinha? (P1, Patu, 2020). 
No início do ano, como eu peguei essa turma aqui, apenas três sabia fazer o nome completo. Então assim, estratégia que eu usei, primeiro conhecer, ter o conhecimento da primeira letra do nome, fiz um... um... a letra do nome... a primeira letra do nome de cada um, colei no palitinho e eu formava círculo todos os dias, sentadinhos com eles no chão, colocava as letrinhas no chão, e ia pedindo a cada um que pegasse a letrinha do nome deles. Pronto, eu iniciei o ano dessa forma, né. (P2, Patu, 2020).

Os enunciados das professoras P1 e P2 demostram que o ensino dos nomes das crianças tem como base a identificação das letras como atividade para compreensão do próprio nome por parte das crianças. O caderno do ano 01 e unidade 7 do PNAIC (BRASIL, 2012b) destaca que a escrita do próprio nome e suas características também é uma boa atividade para o ensino do sistema alfabético, pois as crianças precisam mobilizar o que já sabem (as letras iniciais, por exemplo), e depois tentar registar as palavras. Desse modo, as falas das professoras com relação às concepções teóricas sobre o trabalho com nome das crianças correspondem às orientações disponibilizadas nesse caderno formativo do PNAIC, pois não demostraram a utilização de métodos mecanicistas de repetição e decodificação nas suas práticas de ensino. O nome próprio como modelo de escrita defendido por Morais, Albuquerque e Leal (2005) apresenta-se como a primeira forma escrita dotada de estabilidade e significação, pois é caracterizada como um protótipo de toda escrita posterior.

Nessa perspectiva, percebe-se que um dos pontos principais para as intervenções didáticas no tocante ao ensino do sistema de escrita, é reconhecer as habilidades que precisam ser desenvolvidas, identificando as necessidades de cada aluno e, a partir disso, buscar desenvolver as melhores estratégias didáticas que atendam às necessidades de cada um deles. Nesse momento, é importante que o professor saiba dividir os agrupamentos da turma na hora de desenvolver as atividades voltadas a apropriação das letras, fazendo com que todos os alunos estejam pensando a respeito do sistema que é fundamental naquele momento. A prática pedagógica precisa ser pensada e articulada conforme as necessidades das demandas cognitivas e possibilidades de aprendizagem dos alunos no desenvolvimento da escrita.

O PNAIC estabelece que o trabalho com a escrita precisa considerar as regras para que o aprendiz compreenda a segmentação entre letra-som, e sua variação na formação das palavras. Construímos a partir das entrevistas segunda categoria "Formação de palavras" que está expressa nos seguintes trechos das falas das professoras:

Eu uso. Formação de palavras. Eu... eu tenho um recurso que eu uso demais, demais, demais é o ditado de palavras e esse ditado de palavras eu uso de várias maneiras, eu uso ditado com gravuras pra eles escrever o nome, eu uso o ditadozinho estourado onde tá a palavrinha lá dentro ele vai pegar, eu uso um ditado que eu coloco que o que eles mais gostam eu coloco vários nomes no quadro vários, vários, vários, e daqueles nomes ali eu vou fazer o meu ditado. Então, pra que eles possam também ter a percepção, né? A questão do ouvir. É... de fazer a relação de primeira letra, de última letra. A gente trabalha com esses recursos. (P1, Patu, 2020).

O PNAIC, oferece é.... várias opções pra você trabalhar no início do ano assim porque, é... no início eu coloquei um quadro silábico, né, pra que a criança percebesse, porque você aí, não pode ir na... no... (gaguejando), no tradicional de um B e um A, BA. Um B e um E, BE. Eu já coloquei o quadro silábico no início do ano, pra cada vez que eu tava trabalhando uma atividade com eles, eles iam lá e observava o que formava, com que letras formava a sílaba BA, qual a consoante e qual a vogal, entendeu, iniciamos assim. (P2, Patu, 2020). 
A metodologia que as professoras utilizam para a formação de palavras tem origem nos métodos tradicionais de alfabetização. A professora P1 se baseia no método fônico que relaciona a letra ao seu som tendo como principal estratégia metodológica o ditado para fazer a relação grafo-fônica, sem uma reflexão sonora sobre a escrita das palavras, seus sentidos e significado. A professora P2 demostra em sua fala que se utiliza do método da silabação, pois se apega ao quadro silábico para alfabetizar. Diante dessa realidade, constatamos que a professora P1 procura dar uma nova dinâmica ao ditado, pois apesar de não haver preocupação com os sentidos das palavras que trabalha, mas sim com sua decifração (FRADE, 2007). As orientações do PNAIC do caderno de $n^{\circ} 5$ (BRASIL, 2015, p. 62) enfatizam que "[...] as crianças deverão vivenciar o ensino das relações letras-som e várias regularidades da norma ortográfica”.

Nesse sentido, a apropriação do sistema de escrita a partir da variação das letras e formação das palavras precisa considerar a consciência fonológica, levando o aprendiz a refletir sobre o domínio notacional. A fala da professora P2 demonstra distanciamento do que o PNAIC orienta para trabalhar a variação das letras e a formação de palavras, visto que ela se apropria do ensino da memorização das sílabas sem estar no contexto da palavra. O caderno de $n^{\circ} 5$ (BRASIL, 2015, p. 49) orienta que o aprendizado inicial das crianças na formação das palavras " [...] deve dar-se concomitantemente a apropriação de textos escritos, pois a crianças pode aprender escrever escrevendo de verdade, desde o princípio, para um interlocutor preciso, valendo-se de diferentes gêneros textuais". Nesse sentido, é a partir da construção textual espontânea do aluno que o professor poderá criar estratégias de ensino e intervir da melhor maneira para fazer com que as crianças consigam refletir sobre a variação das letras e a formação das palavras dentro do seu próprio texto e confrontar suas hipóteses iniciais de suas escritas, fazendo-as avançar (MORAIS, ALBUQUERQUE, LEAL, 2005).

Outro aspecto que marca a preocupação com o trabalho com a formação de palavras é o uso de metodologias direcionadas a identificação de sílabas para compreensão das conversões de unidades gráficas e sonoras das palavras na alfabetização das crianças. Isso é possível de verificar nos trechos a seguir:

O som da letra. Eu vou dizer a palavra "BOOOLA" aí qual é o sonzinho? Porque pra isso eles têm que conhecer o som de cada letra, né? E esse... essa... esse ano eu usei muito a questão da técnica da boquinha eu vi foi no... na internet, mas me... utilizei demais dela porque tem várias letras tem letras são coincidem demais o "P" e o "B". E eu comecei fazer essa técnica o "P", o "B" como a minha boquinha faz pra dizer aquela palavra? Aí eles iam observando o som, né? E apesar de dizerem que é muito tradicional o trabalho com quadro silábico na minha sala sempre tem. Gente, mas não existe a criança tem que saber que pra que ela possa escrever a palavra "BALA" ela tem que ter o som do "BA e do "LA". Então, eu trabalho também com a questão do quadro silábico. Pra que eles possam. (P1, Patu, 2020).

É como eu já falei, a melhor a... (pensando), o que melhorou muito na minha sala foi quando eu comecei a trabalhar sílabas, primeiro eles tiveram o conhecimento do que era vogais, e as consoantes, aí veio sílabas. Quando a criança ele tem o conhecimento como eu já falei, o que é sílaba, ele já.... (P2, Patu, 2020).

O PNAIC orienta com base nos pressupostos de Brandão e Leal (2005) que o trabalho das correspondências grafo-fônica deve possibilitar não só decifração das palavras, mas também compreendêla para entender o seu significado (BRASIL, 2015). O posicionamento das professoras P1 e P2 com relação aos conhecimentos teórico-práticos, bem como o método utilizado para trabalhar a variedade de som-grafia, evidenciam algumas divergências com relação às orientações do programa, pois ainda que as professoras reconheçam à importância de se trabalhar a parte fonética das palavras, a metodologia delas baseia-se no 
ensino isolado das letras, vogais, sílabas com ênfase no uso do quadro silábico, sem preocupações com seus contextos de significados. De acordo com o caderno $n^{\circ} 5$ do PNAIC, (BRASIL, 2015) possibilitar que as crianças compreendam as correspondências grafo-fônicas é importante entender as informações implícitas e explícitas das palavras. Nesse sentido, o professor oriente sobre as hipóteses relacionadas ao conteúdo das escritas infantis, as antecipações e inferências, atentando para a construção do sentido das representações das escritas espontâneas das crinaças.

Os cadernos do PNAIC, em especial o caderno do ano 1 e unidade 3 (BRASIL, 2012d, p.28) são orientadas sugestões de atividades interessantes para os professores trabalharem as correspondências som/grafia, dentre elas: "pinte a letras que muda a palavra", "troque a primeira letra e forme outras palavras" e "mude a sílaba de lugar e forme outras palavras". Nesse sentido, percebemos que essas atividades são excelentes recursos para fazer os alunos a refletirem sobre as unidades sonoras e gráficas para pensar e formular outras palavras no processo de ensino aprendizagem do SEA, mas estas não aparecem nas falas dos sujeitos pesquisados que cursaram a formação do PNAIC.

Desenvolver um trabalho pedagógico que se ajuste a heterogeneidade de aprendizagem dos alunos foi um tema que ganhou destaque durante a vigência do programa, visto que esse é um problema que está constantemente presente nas salas de aula, pois apesar dos alunos estarem aproximadamente na mesma faixa etária, não aprende do mesmo modo, no mesmo momento. A esse respeito, o caderno de $\mathrm{n}^{\circ} 5$ do PNAIC (BRASIL, 2015, p 65) destaca que "[...] se quisermos ajudar nossos alunos a resgatarem seus conhecimentos prévios e se aproximarem de novos conhecimentos, precisamos criar, em sala de aula, diferentes zonas de desenvolvimento". Nesse enfoque, é importante que o professor acompanhe as aprendizagens dos alunos com relação ao SEA, de modo a diagnosticar os avanços que forneçam informações para o planejamento e desenvolvimento de atividades com variações, de modo que sejam desafiadoras para cada grupo, e que atenda a diversidade e seus níveis de conhecimentos.

Nesse contexto, é importante também que os professores tenham o auxílio da gestão escolar e das secretarias de educação para realização de procedimentos extraclasse que contribuam na e para aprendizagem dos alunos que não atingiram a hipótese da escrita necessária para sua idade, pois muitas vezes os educadores não conseguem "dar de conta" da demanda diversificada de aprendizagens presente na sala de aula.

As diferenças de aprendizagens e os ritmos que os alunos aprendem são características que estão cada vez mais presentes nas salas de aula, exigindo que o professor mobilize seus conhecimentos para ressignificar seu saber-fazer e atender todas as necessidades. Dessa forma, é a partir da complexidade do trabalho docente que percebemos que a alfabetização é algo que precisa ser refletida no chão da escola. Os programas de formação continuada não podem ser vistos como soluções para os problemas educacionais, e sim como um momento em que os professores constroem e reconstroem seus conhecimentos articulando com as necessidades pedagógicas e os desafios do ato de ensinar, por isso precisam surgir das demandas formativas dos professores.

Assim, percebemos nas falas das professoras que os conhecimentos adquiridos pelo programa privilegiam os recursos didáticos (jogos e ditados) por serem bem mais fáceis de compreender do que os fundamentos teóricos, à aqueles as professoras atribuem maior significação. Portanto, estes farão realmente parte dos saberes como conhecimentos em constante construção se forem compreendidos teoricamente, pois alfabetizar é algo complexo e há necessidade de uma gama de conhecimentos para a promoção desse processo nos anos iniciais do ensino fundamental. 


\section{Considerações finais}

No intuito de analisar as contribuições do PNAIC para o ensino da produção escrita por parte de duas professoras colaboradoras da pesquisa aqui apresentada, foi possível constatar a dificuldade de assimilação dos principais conceitos, objetivos e encaminhamentos metodológicos que a formação continuada do pacto oferecia, comprometendo o desenvolvimento de atividades significativas para produção da escrita das crianças.

As categorias de conteúdo construídas a partir dos dados empíricos revelam que as diferentes concepções teóricas e metodológicas adotadas pelas professoras entrevistadas não se materializam de forma concreta com relação às orientações do PNAIC, pois continuam alfabetizando baseando-se numa concepção de escrita como um sistema de código, com métodos tradicionais de alfabetização - silabação e fonético por enfatizar atividades pedagógicas que objetivam a identificação das letras, sílabas e palavras pelo processo de decodificação, sem relação com a compreensão do contexto em que elas se inserem.

A partir deste estudo compreendemos que a política de formação continuada do PNAIC poderia ter se tornado mais significativa nas práticas das professoras se tivesse havido um maior compromisso com as atividades formativas por parte das docentes, e da gestão escolar com o programa. As práticas pedagógicas só serão ressignificadas mediante a formação quando a teoria e a prática caminharem juntas e os professores percebam que uma complementa a outra, pois o posicionamento das docentes mostra que valorizam o saber prático em detrimento do saber teórico.

\section{Referências}

ANTUNES, I. Aula de português: encontros \& interações. São Paulo: Parábola Editorial, 2003.

BARDIN, L. Análise de Conteúdo. [L'analyse de contenu]. Tradução de Luís Antero Reto e Augusto Pinheiro. Lisboa: Edições 70, 1977. Disponível em: <https://edisciplinas.usp.br/pluginfile.php/4295794/mod_resource/content/1/BARDIN\%2C\%20L.\%20 $\% 281977 \% 29 . \% 20$ An\%C3\%A1lise\%20de\%20conte\%C3\%BAdo.\%20Lisboa_\%20edi\%C3\%A7\%C3 \%B5es\%2C\%2070\%2C\%20225..pdf>. Acesso: 03 dez. 2020.

BRANDÃO, A. C. P; LEAL, T.F. Em busca da construção de sentidos: o trabalho de leitura e produção de textos na alfabetização In: BRANDÃO, A. C. P; Rosa, E. C. de S. (Org.). Leitura e Produção de textos na alfabetização. Belo Horizonte: Autêntica, 2005.

BRASIL. Pacto Nacional Pela Alfabetização na Idade Certa. 1. ed. Brasilia, DF: Diário Oficial, 04 jul. 2012a. v. 1. Disponível em:

<http://www.lex.com.br/legis_23490618_PORTARIA_N_867_DE_4_DE_JULHO_DE_2012.aspx>. Acesso em: 08 nov. 2020.

BRASIL, Ministério da Educação. Pacto Nacional Pela Alfabetização na Idade Certa. Formação de Professores no Pacto Nacional pela Alfabetização na Idade Certa. Brasília: DF, 2017. Disponível em: <http://pacto.mec.gov.br/images/pdf/doc_orientador/doc_orientador_versao_final.pdf $>$. Acesso em: 28 jan. 2021. 
BRASIL, Secretaria de Educação Básica. Pacto Nacional pela Alfabetização na Idade Certa. A oralidade, a leitura e a escrita no ciclo de alfabetização. Caderno 05 / Ministério da Educação, Diretoria de Apoio à Gestão Educacional - Brasília: MEC, SEB, 2015. 112 p. Disponível em:< https://www.novaconcursos.com.br/blog/pdf/pacto-nacional-alfabetizacao-idade-certa-caderno-5.pdf $>$. Acesso em: 10 dez. 2020.

BRASIL, Secretaria de Educação Básica. Pacto Nacional pela Alfabetização na Idade Certa. alfabetização para todos: diferentes percursos, direitos iguais. Caderno 01 / Ministério da Educação, Diretoria de Apoio à Gestão Educacional - Brasília: MEC, SEB, 2012b. Disponível em: <http://www.serdigital.com.br/gerenciador/clientes/ceel/material/39.pdf>. Acesso em: 03 fev. 2021.

BRASIL. Portaria $n^{\circ}$ 867, de 4 de julho de 2012. Institui o Pacto Nacional pela Alfabetização na Idade Certa e as ações do Pacto e define suas diretrizes gerais. In: Diário Oficial da União, Seção 1, No 129 , quinta-feira, 5 de julho de 2012b. Disponível em:

<http://download.inep.gov.br/educacao_basica/provinha_brasil/legislacao/2013/portaria_n867_4julho201 2_provinha_brasil.pdf> Acesso em: 08 de mai. 2021.

BRASIL. Lei no 13.005 , de 25 de junho de 2014 - Aprova o Plano Nacional de Educação (PNE) e dá outras providências. Brasília, Câmara dos Deputados, Edições Câmara, 2014. 86 p. Disponível em: <http://www.observatoriodopne.org.br/uploads/reference/file/439/documento-referencia.pdf >. Acesso em: 19 de maio de 2021.

BRASIL. Lei 10.172, de 9 de janeiro de 2001. Aprova o Plano Nacional de Educação e dá outras providencias. Diário Oficial da União. Brasília, DF, 10 jan. 2001. Disponível em: < http://www.planalto.gov.br/ccivil_03/leis/leis_2001/110172.htm> Acesso em: 20 mai. 2021.

BRASIL. Ministério da Educação. PNA Política Nacional de Alfabetização. Brasília: MEC, SEALF, 2019. Disponível em: <http://portal.mec.gov.br/images/banners/caderno_pna_final.pdf> Acesso em: 21 mar. 2021.

CALKINS, L.; HARTMAN, A.; WHITHE, Z. Crianças produtoras de texto: a arte de interagir em sala de aula. Porto Alegre: Artmed, 2008.

CÂMARA, R. H. Análise de conteúdo: da teoria à prática em pesquisas sociais aplicadas às organizações. Revista interinstitucional de Psicologia, Brasília (2) jul-dez, 2013, 179-191. Disponível em: <http://pepsic.bvsalud.org/pdf/gerais/v6n2/v6n2a03.pdf>. Acesso em: 08 jan. 2021.

FRADE, I. C. A. da S.. Métodos de alfabetização, métodos de ensino e conteúdos da alfabetização: perspectivas históricas e desafios atuais. Revista educação, Santa Maria, v.32, n. 1, jan/jun, 2007. Disponível em: <https://periodicos.ufsm.br/reveducacao/article/view/658/469>. Acesso em: 26 fev. 2021.

GATTI, B. A. Análise das políticas públicas para formação continuada no Brasil, na última década. Revista Brasileira de Educação, Rio de Janeiro, v. 13 n. 37 jan/abr. 2008. Disponível em: <http://www.scielo.br/pdf/rbedu/v13n37/06.pdf>. Acesso em: 15 jan. 2021.

KOCH, I. V.; ELIAS, V. M. Ler e escrever: estratégias de produção textual. 2. Ed., $4^{\mathrm{a}}$ reimpressão. São Paulo: Contexto, 2017. 
LUDKE, M.; ANDRÉ, M. E. D. A.. Pesquisa em educação: abordagens qualitativas. São Paulo: EPU, 1986. (Temas Básicos de Educação e Ensino). Disponível em:

<https://edisciplinas.usp.br/pluginfile.php/4247151/mod_resource/content/2/Lud_And_cap3.pdf $>$. Acesso em: 06 nov. 2020.

MARCUSCHI, L. A. Produção textual, análise de gênero e compreensão. São Paulo: Parábolas Editorial, 2008. Disponível em: http://dlm.fflch.usp.br/sites/dlm.fflch.usp.br/files/MARCUSCHI-LuizAntonio__O-processo-de-producao-textual.pdf>. Acesso em: 02 fev. 2021.

MORAIS, A. G.; ALBUQUERQUE, E. B. C.; LEAL, T. F. Alfabetização: apropriação do sistema de escrita alfabética. Belo Horizonte: Autêntica, 2005. Disponível em:

http://www.serdigital.com.br/gerenciador/clientes/ceel/arquivos/20.pdf>. Acesso em: 12 jan. 2021.

SOARES, M. Letramento e alfabetização: as muitas facetas. Trabalho apresentado na $26^{\circ}$ Reunião Anual da ANPED, Minas Gerais, 2003. Disponível em: http://www.scielo.br/pdf/rbedu/n25/n25a01.pdf>. Acesso em: 19 nov. 2019.

VYGOTSKY, L. S. Pensamento e Linguagem. São Paulo: Martins Fontes, 1989. 